\title{
NOTE BY CHAIRMAN
}

ASTIN stands today in the seventh year of its existence. Its development, in absolute terms, is reflected by the continuous increase in membership, which today exceeds the figure of 500 members. Of more significance, however, has been the scientific activity of ASTIN. Indeed, in these seven years, a substantial impetus has been given to the development of the mathematics of non-life insurance so meeting the urgent and growing practical and theoretical needs of these branches of the insurance industry.

However, this success would not have been achieved without the support and co-operation of its committee and, in particular, its chairmen. The proven diplomatic skill of ASTIN's first chairman, Paul Johansen, ensured a good start and helped greatly to surmount the numerous initial difficulties. Today, Dr. Paul Johansen, in his capacity as Representative of the Permanent Committee, maintains a smooth and effective contact with the parent organisation.

The second chairman, Mr. Marcel Henry, is properly to be regarded as the designer of its so successful colloquia since he has materially influenced the practical shape of these conferences in the course of conducting those held in La Baule and Juan-les-Pins.

The third chairman, Mr. Robert E. Beard, has largely contributed to the crystallisation of ASTIN through his management and direction of the secretarial work over the years, in the course of which not only has a smooth working administration been built up, but also through stimulation and basic research the scientific activity of ASTIN has been greatly enriched.

Besides the three individuals referred to, ASTIN is also greatly indebted to the Chairman of the Permanent Committee, Prof. E. Franckx. In recognition of his services, the general meeting of members held in London on 29th June I964 unanimously voted that he be elected Honorary Chairman of ASTIN.

Considering the records of the previous chairmen, I am very conscious of the honour placed upon me by the committee in electing me to take the chair for the years I $964 / 66$, but not without certain hesitations. However, since two of the past chairmen will also be members of the committee and Prof. Franckx will continue to give his support and advice as our Honorary Chairman, I look forward with confidence to facing the difficulties ahead. This confidence is also strengthened by the support of the other members of the committee, in particular from Mr. Masterson, the new vice-chairman, Mr. P. Thyrion as the new Treasurer and finally by Mr. C. P. Welten who will assist me specially in the editorial work of the ASTIN Bulletin.

ASTIN is thus well placed to face the tasks ahead, of which the next colloquium to be held in Lucerne in 1965 may denote a further important stage in its development.

Hans Ammeter 